\title{
Aerobic transformation of cadmium through metal sulfide biosynthesis in photosynthetic microorganisms
}

\author{
Chad D Edwards, Joseph C Beatty, Jacqueline BR Loiselle, Katya A Vlassov and Daniel D Lefebvre*
}

\begin{abstract}
Background: Cadmium is a non-essential metal that is toxic because of its interference with essential metals such as iron, calcium and zinc causing numerous detrimental metabolic and cellular effects. The amount of this metal in the environment has increased dramatically since the advent of the industrial age as a result of mining activities, the use of fertilizers and sewage sludge in farming, and discharges from manufacturing activities. The metal bioremediation utility of phototrophic microbes has been demonstrated through their ability to detoxify $\mathrm{Hg}(\mathrm{II})$ into $\mathrm{HgS}$ under aerobic conditions. Metal sulfides are generally very insoluble and therefore, biologically unavailable.

Results: When Cd(II) was exposed to cells it was bioconverted into CdS by the green alga Chlamydomonas reinhardtii, the red alga Cyanidioschyzon merolae, and the cyanobacterium, Synechoccocus leopoliensis. Supplementation of the two eukaryotic algae with extra sulfate, but not sulfite or cysteine, increased their cadmium tolerances as well as their abilities to produce $C d S$, indicating an involvement of sulfate assimilation in the detoxification process. However, the combined activities of extracted serine acetyl-transferase (SAT) and O-acetylserine(thiol)lyase (OASTL) used to monitor sulfate assimilation, was not significantly elevated during cell treatments that favored sulfide biosynthesis. It is possible that the prolonged incubation of the experiments occurring over two days could have compensated for the low rates of sulfate assimilation. This was also the case for $\mathrm{S}$. leopoliensis where sulfite and cysteine as well as sulfate supplementation enhanced CdS synthesis. In general, conditions that increased cadmium sulfide production also resulted in elevated cysteine desulfhydrase activities, strongly suggesting that cysteine is the direct source of sulfur for CdS synthesis.

Conclusions: Cadmium(II) tolerance and CdS formation were significantly enhanced by sulfate supplementation, thus indicating that algae and cyanobacteria can produce CdS in a manner similar to that of HgS. Significant increases in sulfate assimilation as measured by SAT-OASTL activity were not detected. However, the enhanced activity of cysteine desulfhydrase indicates that it is instrumental in the provision of $\mathrm{H}_{2} \mathrm{~S}$ for aerobic $\mathrm{CdS}$ biosynthesis.
\end{abstract}

\section{Background}

Cadmium toxicity is a prevalent environmental contaminant, causing adverse effects to a wide variety of ecosystems. As a result, human-cadmium interaction has become more common, posing undesirable health effects in humans. Cadmium is a known carcinogen, and has been linked to renal failure, cellular senescence, and inhibition of essential enzymes responsible for proper cellular function [1-3]. Cadmium acts by displacing $\mathrm{Ca}$ (II) and $\mathrm{Zn}(\mathrm{II})$ as cofactors in numerous enzymes, and it also disrupts membrane potentials [4]. In plants and

\footnotetext{
*Correspondence: lefebvre@queensu.ca

Department of Biology, Queen's University, Kingston, ON K7L 3N6, Canada
}

algae high concentrations of cadmium can negatively affect nitrate, phosphate and sulfate assimilation [5-8], photosynthesis [9], carbohydrate metabolism [10] and plant-water interactions [11]. Similar effects have also been shown to occur in the cyanobacterium, Synechocystis, where it appears that the breakdown of photosynthetic apparatus supplies nutrients for the synthesis of proteins involved in Cd tolerance [12].

Previous research has determined that photosynthetic microorganisms [13-15] and fungi [16] have the capacity to biotransform $\mathrm{Hg}(\mathrm{II})$ into metacinnabar $(\beta \mathrm{HgS})$ under aerobic conditions. Metal sulfides possess low solubilities and, therefore, low toxicities because they are biologically
C Biomed Central

(c) 2013 Edwards et al.; licensee BioMed Central Ltd. This is an Open Access article distributed under the terms of the Creative Commons Attribution License (http://creativecommons.org/licenses/by/2.0), which permits unrestricted use, distribution, and reproduction in any medium, provided the original work is properly cited. 
unavailable. Metal biotransformation of this nature by these organisms was able to remove mercury to levels that conform to the water quality standards of the US Environmental Protection Agency. The exposure of $200 \mathrm{ppb} \mathrm{Hg}$ (II) to the red alga, Galdieria sulphuraria, led to the transformation of $90 \%$ of the $\mathrm{Hg}(\mathrm{II})$ into meta-cinnabar within 20 minutes [14].

The present study was undertaken to determine if $\mathrm{Cd}$ (II) is biotransformed into cadmium sulfide in a similar manner to $\mathrm{Hg}(\mathrm{II})$ under oxic conditions. This was performed in three candidate autotrophic microorganisms, the green alga Chlamydomonas reinhardtii, the red alga Cyanidioschyzon merola, and the cyanobacterium Synechococcus leopoliensis. Because the availability of cysteine and intermediate compounds of sulfate metabolism have been demonstrated to increase the resistance and accumulation of $\mathrm{Cd}(\mathrm{II})$ in plants [11] and protists [17], the effect of supplementation with sulfur containing compounds on cadmium sulfide synthesis was also investigated. The role of the sulfate assimilation pathway was determined by measuring the combined activities of serine acetyl-transferase (SAT, EC 2.3.1.30) and $O$ acetylserine(thiol)lyase (OASTL, EC 4.2.99.8) during Cd(II) exposure. Likewise, cysteine desulfhydrase (EC 4.4.1.1) was measured to see if cysteine could be acting as an important source of sulfide for aerobic metal biotransformation in cyanobacteria and freshwater algae.

\section{Results}

\section{Cadmium tolerance in response to sulfur supplementation}

The autotrophic microalgae, Chlamydomonas reinhardtii and Cyanidioschyzon merolae, and the cyanobacterium, Synechococcus leopoliensis, possess a wide range of tolerances to cadmium. A concentration of $\mathrm{Cd}(\mathrm{II})$ was chosen for each species that retarded, yet did not completely inhibit, growth (Figure 1). For each of the candidate species, the provision of ten times normal sulfate prior to and during exposure to $\mathrm{Cd}$ ions resulted in a significant increase in growth in the cells (ANOVA, p < 0.05). In the cases of Cyanidioschyzon and Synechococcus, under this treatment, cells grew similarly to those grown in the absence of added cadmium (ANOVA, p > 0.05) whereas the Chlamydomonas cells grew to approx. $70 \%$ the biomass of the control. Slight increases in growth occurred during the simultaneous addition of sulfate in all species as well as in Synechococcus that was pre-fed and simultaneously treated with cysteine. Otherwise, treatments with sulfite and cysteine did not result in significant increases in biomass production $(p>0.05)$ and actually had further deleterious effects on growth as shown by similar or less growth than treatments with Cd(II) alone.

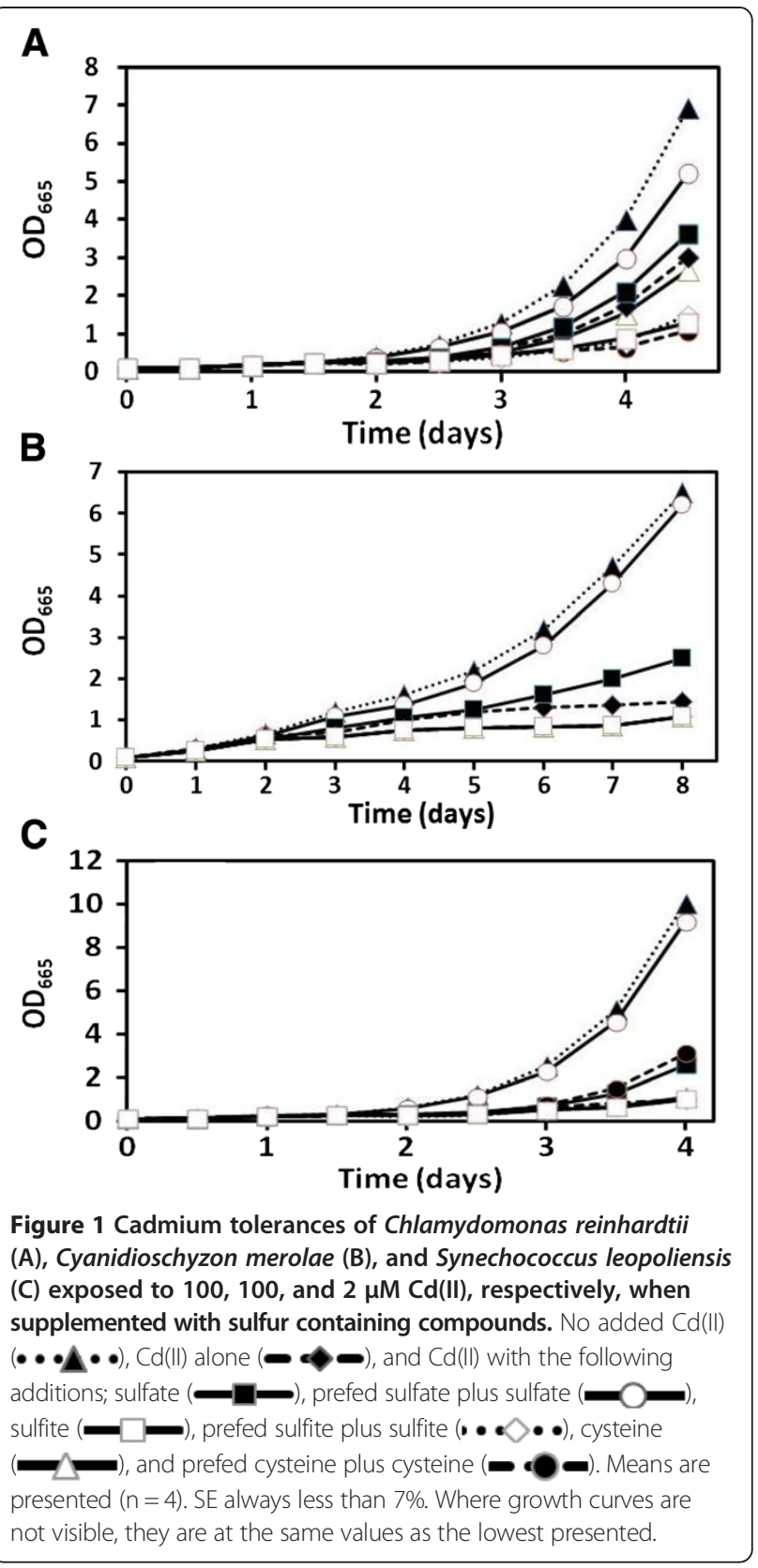

Metal sulfide production

Acid labile sulfide production was measured after 0,1 and 2 days of metal exposure to assess the ability of Chlamydomonas and Cyanidioschyzon to bioconvert $100 \mu \mathrm{M}$ of $\mathrm{Cd}$ (II) (Figure 2A, B). Similar measurements were applied to Synechococcus treated with $2 \mu \mathrm{M} \mathrm{Cd}$ (II) (Figure 2C). In all treatment conditions the highest amount of sulfide was produced by Cyanidioschyzon, especially when cells were supplemented with sulfate during metal exposure and even more when also pretreated with extra sulfate (Figure 2B; $\mathrm{p}<0.05)$. Similar trends also occurred but not to the same degree in Chlamydomonas (Figure 2A; $\mathrm{p}<0.05$ ). The highest amounts of metal sulfide production were 3.5 (approx. 64 

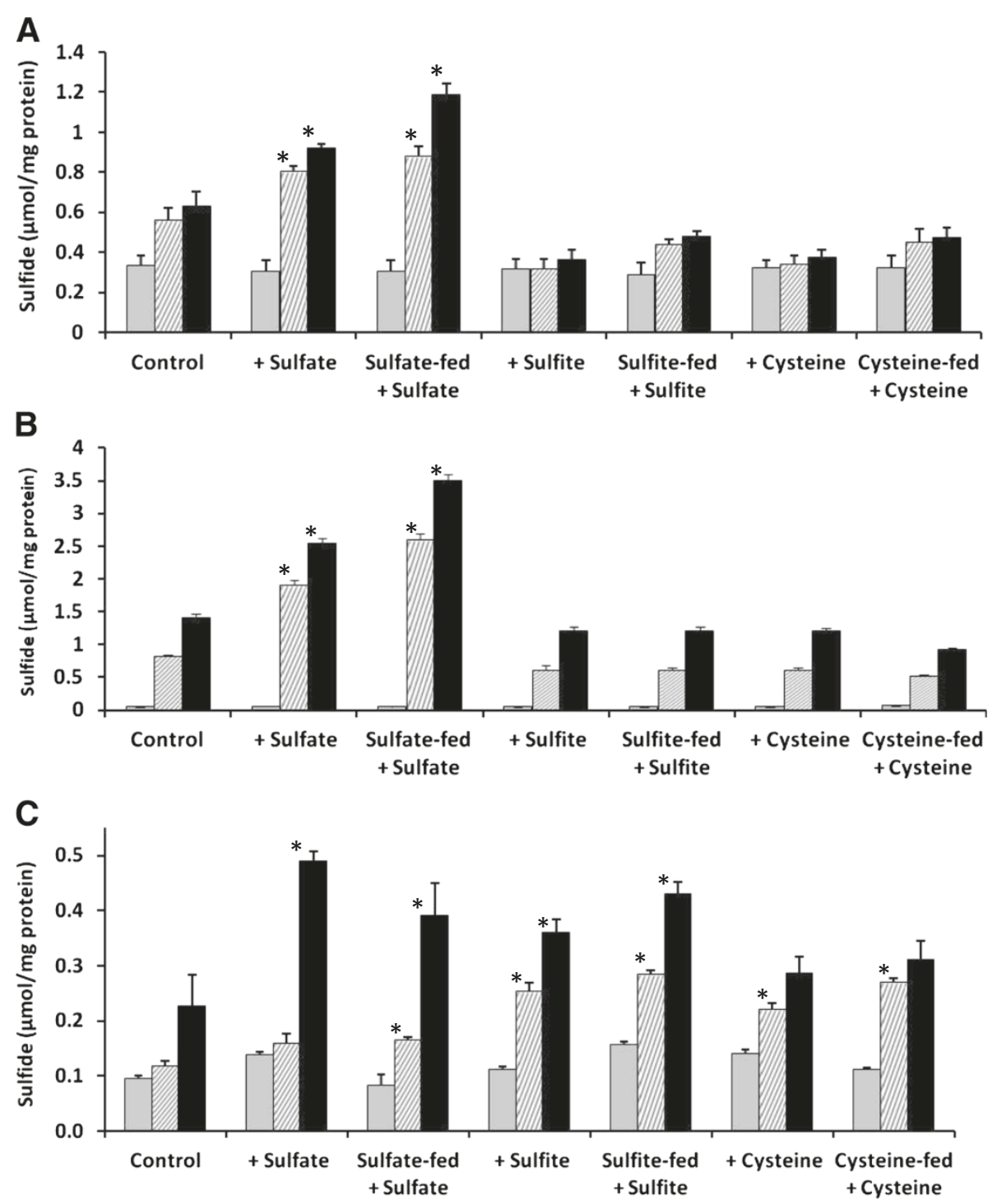

Figure 2 Cadmium induced sulfide formation at 0 (grey), 24 (cross-hatched) and $48 \mathrm{~h}$ (black) for Chlamydomonas reinhardtii (A) and Cyanidioschyzon merolae (B) in $100 \mu \mathrm{M} \mathrm{Cd(II),} \mathrm{and} \mathrm{Synechococcus} \mathrm{leopoliensis} \mathrm{(C)} \mathrm{in} 2 \mu \mathrm{M} \mathrm{Cd(II).} \mathrm{Means} \mathrm{and} \mathrm{SE} \mathrm{(} n=4)$. An asterisk indicates significantly greater than the respective $\mathrm{Cd}(\mathrm{II})$ containing control $(\mathrm{p}<0.05)$.

fold increase) and $1.2 \mu \mathrm{mol}$ per mg protein (approx. 4 fold increase) for Cyanidioschyzon and Chlamydomonas, respectively. The cyanobacterium Synechococcus in the sulfate pretreated cells produced a much lower amount of metal sulfide at $0.48 \mu \mathrm{mol}$ per mg protein (approx. 3.5 fold increase) and this required $48 \mathrm{~h}$ to become significantly different from the control. However, this species was exposed to only $2 \mu \mathrm{M} \mathrm{Cd}(\mathrm{II})$, one fiftieth that of the other species because it is not as tolerant to cadmium. In contrast to the two eukaryotic algal species, the cyanobacterium also made similar amounts of metal sulfides during sulfite treatments. No species made significantly more sulfide as a product of cysteine supplementation after $48 \mathrm{~h}$, although Synechococcus did make significantly more after $24 \mathrm{~h}$.
Serine acetyltransferase and $O$-acetylserine(thiol)lyase coupled activity

Each species had significantly different initial SAT/OASTL activities under control conditions (ANOVA, $\mathrm{p}<0.05$; Figure 3). Exposure to $\mathrm{Cd}(\mathrm{II})$ enhanced the activity of coupled SAT and OASTL over controls with no added metal after 48 hrs to 2.0, 1.7, and 3.2 fold in Chlamydomonas (Figure 3A), Cyanidioschyzon (Figure 3B), and Synechococcus (Figure 3C), respectively. This treatment also resulted in the highest enzyme activities in each of the species. The only other $\mathrm{Cd}(\mathrm{II})$ treatments that were higher than the controls in all three species were the simultaneously sulfate fed, and the pre- and simultaneously sulfite fed cells. The pre- and simultaneously cysteine-fed 

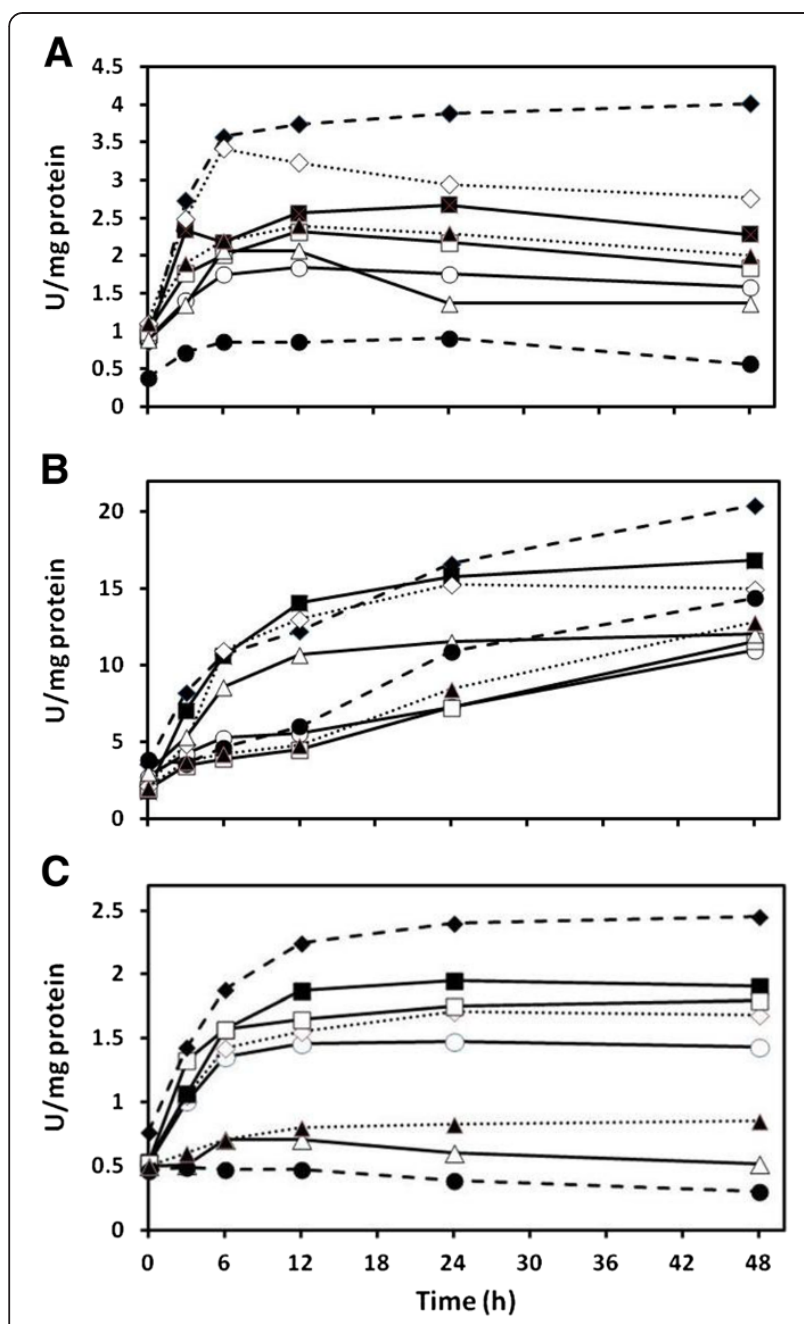

Figure 3 Effect of cadmium on coupled serine acetyl-transferase and $O$-acetylserine(thiol)lyase activity in Chlamydomonas reinhardtii (A), Cyanidioschyzon merolae (B), and Synechococcus leopoliensis (C) exposed to 100, 100, and $2 \mu \mathrm{M} \mathrm{Cd}(\mathrm{II})$, respectively, when supplemented with sulfur

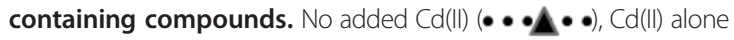

$(-\infty)$, and $\mathrm{Cd}(\mathrm{II})$ with the following additions; sulfate prefed sulfate plus sulfate $(\mathbf{O}-$ ), sulfite $(\boldsymbol{\square}-$ ), prefed sulfite plus sulfite $(\boldsymbol{\bullet \bullet \bullet ) , ~ c y s t e i n e ~ ( ~}$ cysteine $(\mathbf{0} \mathbf{- O})$. Means are presented $(n=4)$. SE always less than $6 \%$.

Chlamydomonas and Synechococcus had the lowest activities (ANOVA, $\mathrm{p}<0.05$ ), although this was not the case for Cyanidioschyzon. In the latter species the treatments with the lowest activities did not differ from the control, and the pre- and simultaneously cysteine-fed cells were significantly different from the control (ANOVA, p < 0.05).

Major differences between the species include the overall high SAT/OASTL activities and the relatively high pre- and simultaneously cysteine-fed treatment in Cyanidioschyzon
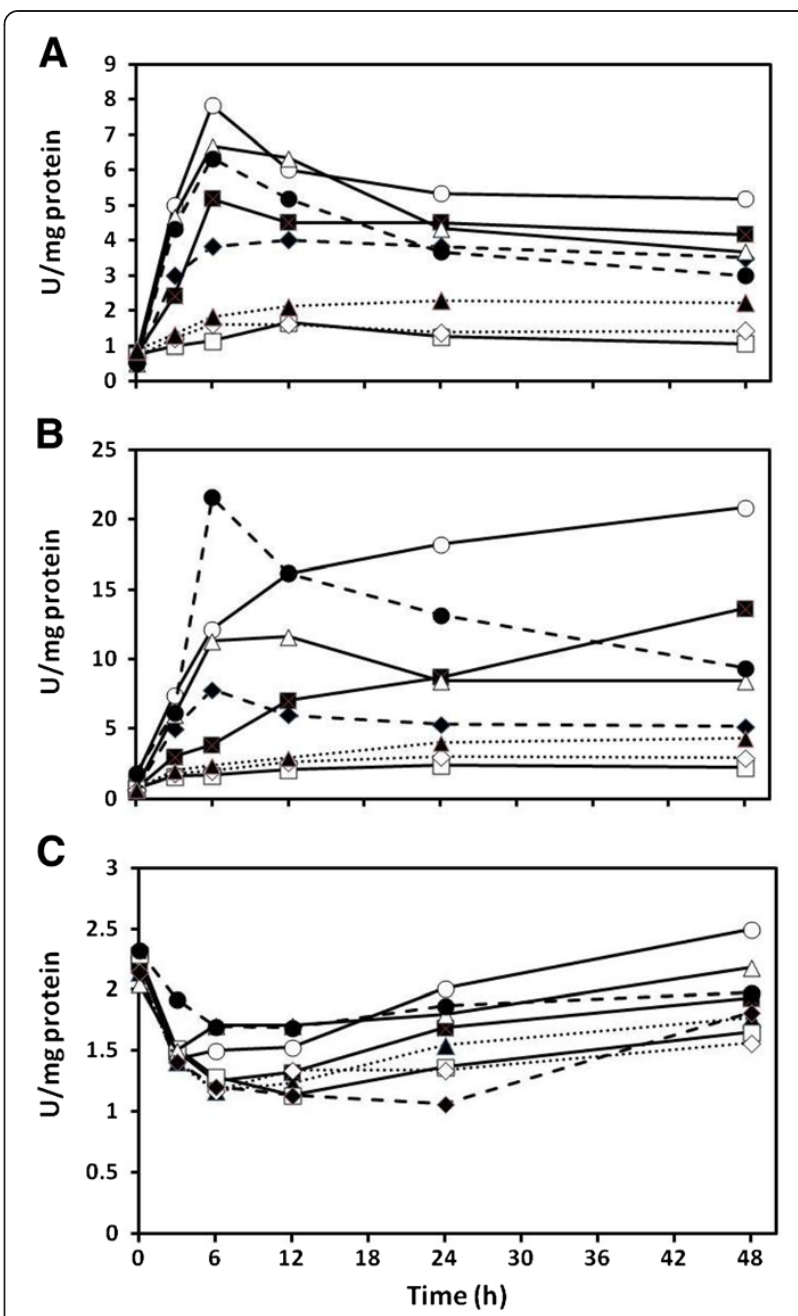

Figure 4 Effect of cadmium on cysteine desulfhydrase activity in Chlamydomonas reinhardtii (A), Cyanidioschyzon merolae (B), and Synechococcus leopoliensis (C) exposed to 100, 100, and $2 \mu \mathrm{M} \mathrm{Cd}(\mathrm{II})$, respectively, when supplemented with sulfur containing compounds. No added $\mathrm{Cd}(\|)(\boldsymbol{\bullet \bullet \bullet \bullet \bullet \bullet ) , ~} \mathrm{Cd}(\|)$ alone

$(-\mathbf{C})$, and $\mathrm{Cd}(\mathrm{II})$ with the following additions; sulfate ( prefed sulfate plus sulfate $(-\mathrm{O}-$ ), sulfite $(\square \square)$, prefed sulfite

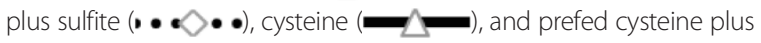
cysteine $(\mathbf{0}-)$. Means are presented $(n=4)$. SE always less than $7 \%$.

and the relatively low pre- and simultaneous cysteine-fed treatment in Chlamydomonas and Synechococcus.

\section{Cysteine desulfhydrase}

The presence of $\mathrm{Cd}(\mathrm{II})$ increased cysteine desulfhydrase activity over that of the metal free control in only one of the three investigated species, Chlamydomonas (Figure 4). However, of the $\mathrm{Cd}(\mathrm{II})$ treatments the pre- and simultaneously sulfate fed cells had the highest activity in all species after $48 \mathrm{~h}$ (ANOVA, $\mathrm{p}<0.05$ ). Under these conditions, Cyanidioschyzon had the highest cysteine 
desulfhydrase activity after $48 \mathrm{~h}$ at $21.5 \mathrm{U} / \mathrm{mg}$ protein, followed by Chlamydomonas at $7.8 \mathrm{U} / \mathrm{mg}$ protein, and Synechococcus at only $2.5 \mathrm{U} / \mathrm{mg}$ protein. Simultaneous metal and sulfate treatments consistently had the second highest final activities in the eukaryotic species, whereas for Synechococcus, it was the simultaneous cysteine treatment. All of the Chlamydomonas and Cyanidioschyzon treatments started with an increase in activity whereas cysteine desulfhydrase activity actually initially decreased in all Synechococcus cultures (Figure 4C) followed by slow recoveries up to $48 \mathrm{~h}$ (Figure $4 \mathrm{C}$ ). In the eukaryotic species, both types of cysteine treatments gave transient increases with peak activities at $6 \mathrm{~h}$ followed by decreases in activity. All sulfide treatments resulted in relatively low cysteine desulfhydrase activities.

\section{Discussion}

Our previous studies on $\mathrm{Hg}(\mathrm{II})$ biotransformation have shown that it can be converted into metacinnabar $(\mathrm{HgS})$ in both eukaryotic algae [14] and prokaryotic cyanobacteria [15]. However, these studies did not investigate supplementation with sulfur containing compounds, nor did they assess metal sulfide production in response to $\mathrm{Cd}(\mathrm{II})$ exposure. Cadmium is also a Group 12 stable metal that is very toxic and widely distributed in the environment.

\section{Tolerance to $\mathrm{Cd}(\mathrm{II})$}

The levels of $\mathrm{Cd}(\mathrm{II})$ tolerance of the algae and cyanobacteria were similar to previous studies [18], and the addition of sulfate to all of the investigated species both prior to and during metal exposure resulted in higher tolerance to $\mathrm{Cd}(\mathrm{II})$ than any other treatment (Figure 1). These cultures were either the same as (Cyanidioschyzon and Synechococcus) or only slightly lower in biomass (Chlamydomonas) over the $48 \mathrm{~h}$ growth period by comparison to the metal-free controls. Although cadmium stress has been shown to induce sulfur limiting conditions $[7,19]$, this was not entirely alleviated by the simultaneous provision of sulfate in any of the studied species, thus indicating that established metabolic reserves of sulfur other than sulfate itself, may be involved in cellular protection. Furthermore, it has been demonstrated that $\mathrm{Cd}$ exposure triggers a decline of photosynthetic apparatus thereby liberating sulfur as well as nitrogen and iron, which can be subsequently used for the synthesis of Cd detoxification enzymes [12]. Assimilated sulfate appears to create an organic sulfur pool that can be readily employed to biotransform $\mathrm{Cd}(\mathrm{II})$ as it enters the cell in a similar manner to that proposed for $\mathrm{Hg}$ (II) where chemical modification of thiols severely lessened HgS production $[14,15]$. Why this cannot be provided by simultaneous sulfate provision is likely to be a product of the high energy demand $\left(732 \mathrm{~kJ} \mathrm{~mol}^{-1}\right)$ required to reduce sulfate to sulfide for thiol production, energy required for sulfate uptake, and the decline in sulfate uptake induced by cadmium itself [12]. These organisms rely on photosynthesis to generate reducing power that is essential for carbon fixation. If this is shunted towards sulfate assimilation, it would inhibit cellular metabolism and growth. By temporally displacing energy requirements to a pretreatment period, this is overcome and the cells are able to adequately cope with any stress imposed by subsequent exposure to $\mathrm{Cd}(\mathrm{II})$. The simultaneous sulfate and metal treated cells grew marginally better than the cells treated with metal alone in Cyanidioschyzon and Synechococcus (Figures 1B \& C), but not in Chlamydomonas. Metabolic differences might account for this; i.e. the former species may have relatively more efficient sulfate assimilation. Interestingly, in a separate study it was revealed that Synechococcus is able to utilize elemental sulfur as a sulfur source resulting in enhanced metal tolerance (data not shown). These results point to the importance of sulfur nutrition in cadmium tolerance that has implications for other organisms $[20,21]$, including humans [22]. Nevertheless, this has not been well documented in the literature.

The other treatment in which Synechococcus grew better than in cadmium alone was that in which cysteine was supplied both prior to and during metal exposure. However, this cannot be accounted for by a relatively high cysteine desulfhydrase activity in Synechococcus (Figure 4). Both eukaryotic species were not as adept at coping with this form of sulfur supplementation.

In general, pretreatments with sulfite, an intermediate of the sulfate assimilation pathway, and with the amino acid, cysteine, did not provide ameliorative effects on growth during $\mathrm{Cd}(\mathrm{II})$ exposure to the same degree as sulfate. Sulfite can be toxic to green algae [23] because of interactions with sulfide bonds of glutathione and glutathione disulfide that severely affect anti-oxidation processes [24]. It can also lead to $\mathrm{SO}_{2}$ toxicity through sulfoxy-free radicals generated by the oxidation of $\mathrm{SO}_{3}^{2-}$ by $\mathrm{O}_{2}^{-}$[23]. Furthermore, in membrane preparations of cyanobacteria, sulfite stimulates ATP hydrolysis and inhibits ATP synthesis [25]. Exogenous cysteine is believed to have direct effects on transporters and enzymes that are sensitive to thiol/disulfide redox variations [26]. This could account for the deleterious effects on the eukaryotic organisms in this study as unfortunately, these treatments did not improve $\mathrm{Cd}(\mathrm{II})$ tolerance. However, cysteine did improve the growth of Synechococcus in the presence of cadmium. It is possible that this organism is not as susceptible to functional interference of its protein thiol groups, or that it has a greater absorption and storage capacity for cysteine, thereby lowering its deleterious effects.

\section{Cellular sulfide production}

The measurement of acid labile sulfide is a convenient way to estimate amounts of metal sulfide within samples 
[27]. Our studies clearly indicated that the addition of $\mathrm{Cd}(\mathrm{II})$ caused de novo aerobic synthesis of metal sulfide, assumed to be predominantly $\mathrm{CdS}$ because there was no detected increase in metal sulfides when Cd(II) was not supplied to the cells under any conditions (data not shown). This production of metal sulfide was generally comparable to that of $\mathrm{HgS}$ in our previous studies [13-15], and it was produced to a higher level in the more rapidly growing eukaryotic cell treatments (Figure 2A \& B). The cyanobacterium, Synechococcus, was able to synthesize significantly higher amounts of metal sulfide over time under all investigated conditions, although it is much less tolerant to $\mathrm{Cd}(\mathrm{II})$ than the eukaryotic species. Heavy metals are known to bind with low molecular weight thiol compounds such as glutathione and phytochelatins $[28,29]$. The latter are low molecular weight metallothioneins synthesized from glutathione [17]. Like metal sulfides, per se, metals bound in this way are more stable and less likely to cause oxidative damage. Cytosolic fractions taken from species of cyanobacteria and algae after exposure to $\mathrm{Cd}(\mathrm{II})$ have shown that approximately $30 \%$ of these metals are bound with metallothioneins, including phytochelatins [30-32]. Metallothioneins can exist as low and high molecular weight variants. In low molecular weight forms the metal is bound to thiol groups, whereas in the high molecular weight forms, additional inorganic sulfur is incorporated into the complexes [33] which appear to stabilize and improve detoxification. Interestingly, it is this pool of inorganic sulfur that is probably associated with $\mathrm{Cd}$ to form CdS.

Sulfate treatments resulted in more production of cellular metal sulfide by comparison with the treatment with $\mathrm{Cd}(\mathrm{II})$ alone in all investigated species (Figure 2). This took longer to become apparent in the cyanobacterial species ( $48 \mathrm{~h}$, Figure $2 \mathrm{C}$ ) where significant differences from the control also occurred in the sulfite and cysteine treatments. The latter was not the case for Chlamydomonas or Cyanidioschyzon. Here again, this could be accounted for by sulfur metabolism differences between cyanobacteria and algae, or possibly distinct tolerances to the toxic effects of these metabolites. High rates of sulfite assimilation into amino acids [34] and high expression of SSU1, a sulfite efflux gene [35], are known to result in lower toxicity to sulfite in yeast. Similar mechanisms may also occur in Synechococcus.

The thermophilic red microalga, Cyanidioschyzon, was capable of biotransforming approximately three times as much $\mathrm{Cd}(\mathrm{II})$ into metal sulfide as the mesophilic green alga, Chlamydomonas, when both were grown in $100 \mu \mathrm{M}$ $\mathrm{Cd}(\mathrm{II})$. This ability may be accounted for by its adaptation to sulfur-rich hot springs [36]. In fact, the Cyanidium medium [37] used to grow Cyanidioschyzon contains over an order of magnitude more sulfate than the high salt medium conventionally used for Chlamydomonas. The sensitivity of Synechococcus to $\mathrm{Cd}(\mathrm{II})$ is much higher than in the eukaryotic species. Nevertheless, metal biotransformation into sulfide by this species was only about half of that for Chlamydomonas, indicating that although sensitive to cadmium, it was able to transform a high proportion of the $\mathrm{Cd}(\mathrm{II})$ into metal sulfide. The fact that Synechococcus can convert a relatively high amount of $\mathrm{Cd}$ (II) into metal sulfide while remaining very sensitive to $\mathrm{Cd}$ (II), might be attributed to a relatively high susceptibility to displacement of metals by $\mathrm{Cd}$ as cofactors in photosynthetic and other metabolic enzymes, and to disruption of membrane function [4]. Similarly, this could account for the differences between the algal species.

The first report of acid labile sulfide in living organisms was in association with metallothioneins and phytochelatins in fission yeast [38], and it is known that metallothionein gene amplification can confer resistance to cadmium in Synechococcus PCC 6301 [39]. Algal phytochelatins bind cadmium in relatively low metal to peptide amounts [40] and it is likely that CdS formed in the organisms in the present study are mainly in the form of precipitated nanoparticles, examples of which have been reported in as diverse organisms as Klebsiella [41], marine microalgae [33], tomatoes [42] and mustard plants [43]. This, however, remains to be confirmed.

\section{Sulfate assimilation}

Most organisms absorb sulfur from the environment in the form of inorganic sulfate and active transport systems for sulfate uptake have been investigated extensively in algae [44-46], bacteria [47], yeast [48], and higher plants [49,50].

Algae and cyanobacteria appear to undergo sulfur assimilation in a similar manner [51,52]. Absorbed sulfate is first converted to adenylylsulfate (APS) by ATP sulfurylase. Adenylylsulfate is then further reduced by APS reductase to yield sulfite which in turn is converted to sulfide by sulfite reductase. This sulfide is immediately transferred to the serine acetyltransferase/O-acetylserine (thiol)lyase bi-enzymatic complex (SAT-OASTL) that covalently binds it to serine to produce cysteine [50,51]. Because all assimilated sulfate is converted into cysteine via SAT-OASTL, measuring these enzymes' coupled activity provides a convenient means of comparing sulfate assimilation between species in response to various treatments.

The activities of SAT-OASTL in Chlamydomonas were similar to those of Ravina and colleagues [52] in the non-metal controls. In addition, their sulfite treatment had a similar activity to the pre- and simultaneously fed sulfite treatment in the present study. However, it is difficult to assess the effect of sulfite on specific enzymes because of its cellular toxicity (Figure 1A), something that was not considered in the previous study. The highest enzyme activities occurred when $\mathrm{Cd}(\mathrm{II})$ was 
provided without any supplemental sulfur containing compounds, a state in which sulfur reserves of the cells would be consumed in the $\mathrm{CdS}$ synthetic process (Figure 2A). Sulfur starvation has been previously shown to significantly up-regulate OASTL activity [52] as has $\mathrm{Cd}(\mathrm{II})$ exposure ([5], but this has never been studied in the context of aerobic cadmium sulfide synthesis. The highest bioconversion of $\mathrm{Cd}(\mathrm{II})$ into metal sulfide was performed when Chlamydomonas was supplemented with extra sulfate. However, this did not result in significant differences in SAT-OASTL activity from the non-metal control which was significantly lower than the $\mathrm{Cd}(\mathrm{II})$ control. This could be because Cd-elicited sulfur deprivation in the cells is compensated for by sulfate provision.

Similar to Chlamydomonas, both Cyanidioschyzon and Synechococcus possessed the highest SAT-OASTL activities during the $\mathrm{Cd}(\mathrm{II})$ control conditions. However, unlike in Chlamydomonas, simultaneous sulfate treatments had significantly higher activities than the non-metal controls (ANOVA, $\mathrm{p}<0.05$ ). This appears to be contradictory because these cells have higher S-nutrition than the controls and it has been shown that S-deprivation enhances OASTL activity [52]. However, Cd-induced S-deprivation does not appear to be compensated for by the simultaneous provision of sulfate whereas extra sulfate provided by additional pre-treatments did lower enzyme activity to closer to the control levels, thereby revealing an S-nutritional effect.

Major differences occurred in the cysteine treatments between Chlamydomonas and Synechococcus that displayed expected low activities compared to controls, and the higher activities observed in Cyanidioschyzon. This could be explained by the latter species' adaptation to sulfur-rich hot spring environments $[36,53,54]$, as its SATOASTL activities were generally a magnitude higher than in the other species. Cyanidioschyzon enzymes need not be regulated as stringently as for Chlamydomonas and Synechococcus given that sulfur would never normally become limiting in its native environment where it could utilize the sulfur assimilation pathway for metal detoxification without experiencing the threat of sulfur depletion. Lending support to this notion is that this red alga possesses one additional SAT and two additional OASTL homologues [55]. However, it synthesized more CdS only under sulfate-, and not sulfite- or cysteine-supplemented conditions in a similar manner to Chlamydomonas, and in contrast to Synechococcus where all conditions gave significant increases in acid labile sulfide production (Figure 2C).

The extracted activity of SAT-OASTL indicates that these enzymes do play a role in the production of required assimilated sulfur for cadmium sulfide as it was highest when cells were exposed to $\mathrm{Cd}(\mathrm{II})$ without sulfate supplementation. Higher plants that have been genetically engineered to have higher levels of these enzymes have shown some increased resistance to $\mathrm{Cd}(\mathrm{II})$ $[11,56]$ and other metals [57]. Bearing in mind that in vivo activity would be distinct from extracted activity because of, among other things, different substrate concentrations, it is likely that sulfur flux through SATOASTL would be higher in the sulfate supplemented cells, which could contribute to the respective elevated $\mathrm{CdS}$ production.

\section{Enzymatic sulfide production}

Hydrogen sulfide, traditionally considered a toxic compound, has recently been implicated in cellular signaling $[58,59]$. However, it would be expected that metal sulfide biosynthesis should require more sulfide than signaling processes. Several metabolic sources of sulfide have been proposed [60] and of these, cysteine desulfhydrase activity is the most evident and is accentuated by feeding with cysteine [61]. In addition, there is some evidence that sulfide is released during excess sulfate nutrition which can be through provision of sulfate or sulfur dioxide/sulfite [62]. This appears to be because of inadequate cellular supplies of $O$-acetylserine [63] and as such, OASTL cannot utilize all the $\mathrm{H}_{2} \mathrm{~S}$ generated by sulfite reductase. This could have occurred in the sulfate supplemented cultures of this study, particularly in the case of Cyanidioschyzon where the sulfate concentration was 108.6 mM, however sulfate in the media of the other two species was relatively low. Other metabolic sources of significant amounts of $\mathrm{H}_{2} \mathrm{~S}$ are speculative.

The assayed activity of cysteine desulfhydrase was generally much higher in Cyanidioschyzon than in Chlamydomonas and Synechococcus (Figure 4) as was the case for SAT-OASTL (Figure 3). This further indicates adaptation to high sulfur environments that accounts for its elevated ability to biotransform $\mathrm{Cd}$ (II) into metal sulfide which is insoluble and therefore, non-toxic. The highest activity of all was at only $6 \mathrm{~h}$ in the pre- and simultaneous treatment of Cyanidioschyzon with cysteine, but this did not result in an enhanced production of metal sulfide. In fact, both types of cysteine treatments in all species had relatively high cysteine desulfhydrase activities at $6 \mathrm{~h}$ with no enhanced metal sulfide production. Unfortunately, treatments with lower amounts of cysteine did not result in detectable increases in metal sulfide production (data not shown). This implies that the enzyme may not be involved in the supply of sulfide for CdS synthesis, or that excess cysteine is inhibitory. The latter is likely because supplementation with sulfate prior to and during $\mathrm{Cd}(\mathrm{II})$ exposure resulted in the highest desulfhydrase activities after $24 \mathrm{~h}$ in all three species as well as the highest production scenarios for metal sulfide. In addition, the simultaneous addition of 
extra sulfate with $\mathrm{Cd}(\mathrm{II})$ also resulted in relatively high extracted enzyme activity. This is consistent with the fact that Escherichia coli genetically engineered to contain unregulated cysteine desulfhydrase do produce elevated amounts of CdS $[64,65]$, and the formation of CdS nanoparticles appears to increase with extractable cysteine desulfhydrase activity in the photosynthetic bacterium Rhodopseudomonas palustris [66]. Although the accumulation of acid labile sulfide is high in the organisms presented in this study, it remains to be seen if they comprise CdS nanoparticles.

\section{Conclusions}

The fact that cadmium tolerance was significantly enhanced by sulfate supplementation is supported by the discovery of the enhanced formation of metal sulfides under these conditions. Because $\mathrm{Cd}(\mathrm{II})$ was provided in the media in a much higher excess than other metal ions, the increase in acid labile sulfides can be attributed to CdS formation. The cyanobacterium Synechococcus leopoliensis, the green alga Chlamydomonas reinhardtii, and especially the red alga Cyanidioschyzon merolae produce high quantities of $\mathrm{CdS}$ in a manner that appears to be similar to HgS biosynthesis ([13-15]. The addition of sulfate increased this production dramatically indicating the involvement of sulfate assimilation. Although SATOASTL was not shown to increase significantly under sulfate supplementation, the relatively long-term duration of this study could account for the accumulation of reserves used to make the sulfide moiety of $\mathrm{CdS}$. The identity of these reserves could be glutathione or possibly sulfur mobilized from the breakdown of photosynthetic apparatus [12]; however, this remains to be determined. Whereas the role of SAT-OASTL appears to be pedestrian, cysteine desulfhydrase can be implicated in the production of $\mathrm{CdS}$ because it does possess elevated activity during conditions conducive to metal sulfide production.

\section{Methods}

\section{Culture sources and growth conditions}

The eukaryotic alga Chlamydomonas reinhardtii (UTEX 90) was obtained from the Culture Collection of Algae, University of Texas at Austin. Cultures were grown in high salt medium (HSM) [67] composed of $9.35 \mathrm{mM}$ $\mathrm{NH}_{4} \mathrm{Cl}, 8.27 \mathrm{mM} \mathrm{K} \mathrm{HPO}_{4}, 5.44 \mathrm{mM} \mathrm{KH_{2 }} \mathrm{PO}_{4}, 0.09 \mathrm{mM}$ $\mathrm{CaCl}_{2}, 0.081 \mathrm{mM} \mathrm{MgSO} \cdot 7 \mathrm{H} 2 \mathrm{O}, 3 \mu \mathrm{M} \mathrm{H}_{3} \mathrm{BO}_{3}, 2.1 \mu \mathrm{M}$ $\mathrm{MnCl}_{2} \cdot 4 \mathrm{H}_{2} \mathrm{O}, 1 \mu \mathrm{M} \mathrm{Na}{ }_{2}$ EDTA $2 \mathrm{H}_{2} \mathrm{O}, 0.6 \mu \mathrm{M} \mathrm{FeCl} \mathrm{Cl}_{3} \cdot 6 \mathrm{H}_{2} \mathrm{O}$, $0.03 \mu \mathrm{M} \mathrm{NaMoO} \cdot 2 \mathrm{H}_{2} \mathrm{O}, 0.025 \mu \mathrm{M} \mathrm{ZnCl}, 0.01 \mu \mathrm{M}$ $\mathrm{CoCl}_{2} \cdot 6 \mathrm{H}_{2} \mathrm{O}, 0.07 \mathrm{nM} \mathrm{CuCl} 2 \cdot 2 \mathrm{H}_{2} \mathrm{O}$ in double deionized water. Cyanidioschyzon merolae 10D was acquired from the Microbial Culture Collection of the National Institute for Environmental Studies (Tsukuba, Japan). Cyanidioschyzon was propagated using a Cyanidium medium [37] composed of $9.85 \mathrm{mM}\left(\mathrm{NH}_{4}\right)_{2} \mathrm{SO}_{4}, 2.06 \mathrm{mM} \mathrm{K}_{2} \mathrm{HPO}_{4}$,
$1.01 \mathrm{mM} \mathrm{MgSO}_{4} \cdot 7 \mathrm{H}_{2} \mathrm{O}, 0.67 \mathrm{mM} \mathrm{CaCl}_{2}, 13 \mu \mathrm{M} \mathrm{Na}_{2}$ EDTA, $3.0 \mu \mathrm{M} \mathrm{H}_{3} \mathrm{BO}_{3}, 2.2 \mu \mathrm{M} \mathrm{FeCl}{ }_{3} 6 \mathrm{H}_{2} \mathrm{O}, 1.2 \mu \mathrm{M} \mathrm{MnCl}_{2} \cdot 4 \mathrm{H}_{2} \mathrm{O}$, $0.32 \mu \mathrm{M} \mathrm{CuSO}{ }_{4} \cdot 5 \mathrm{H}_{2} \mathrm{O}, 0.22 \mu \mathrm{M} \mathrm{ZnSO} 4.7 \mathrm{H}_{2} \mathrm{O}, 0.12 \mu \mathrm{M}$ $\mathrm{Na}_{2} \mathrm{MoO}_{4}$ and $0.05 \mu \mathrm{M} \mathrm{CoCl} \mathrm{C}_{2} 6 \mathrm{H}_{2} \mathrm{O}$ in double deionized water. The medium was adjusted to $\mathrm{pH} 3.5$ with $\mathrm{HCl}$. Synechococcus leopoliensis (UTEX 2434), a cyanobacteria species, was obtained from the Culture Collection of Algae, University of Texas at Austin. Cells were grown in medium using 50X Cyanobacteria BG-11 Freshwater Solution (Sigma Aldrich, catalogue \# C3061) [68] that was diluted to $1 \mathrm{X}$ in double deionized water to final concentrations of: $17.65 \mathrm{mM} \mathrm{NaNO} 3,0.3 \mathrm{mM} \mathrm{MgSO} \cdot 7 \mathrm{H}_{2} \mathrm{O}, 0.24 \mathrm{mM}$ $\mathrm{CaCl}_{2} \cdot 2 \mathrm{H}_{2} \mathrm{O}, 0.18 \mathrm{mM} \mathrm{K}_{2} \mathrm{HPO}_{4}, 46.0 \mu \mathrm{M} \mathrm{H}_{3} \mathrm{BO}_{3}, 31 \mu \mathrm{M}$ citric acid, $21 \mu \mathrm{M}$ ferric ammonium citrate, 9.1 $\mu \mathrm{M}$ $\mathrm{MnCl}_{2} \cdot 4 \mathrm{H}_{2} \mathrm{O}, 2.8 \mu \mathrm{M} \mathrm{MnNa}_{2}$ EDTA, $1.7 \mu \mathrm{M} \mathrm{NaMoO}_{4} \cdot 2 \mathrm{H}_{2} \mathrm{O}$, $0.77 \mu \mathrm{M} \mathrm{ZnSO}_{4} \cdot 7 \mathrm{H}_{2} \mathrm{O}, 0.32 \mu \mathrm{M} \mathrm{CuSO}_{4} \cdot 5 \mathrm{H}_{2} \mathrm{O}, 0.17 \mu \mathrm{M}$ Co $\left(\mathrm{NO}_{3}\right)_{2} \cdot 6 \mathrm{H}_{2} \mathrm{O}$. All chemicals were obtained from SigmaAldrich (Oakville, Canada) or Fisher Scientific (Ottawa, Canada). Synechococcus and Chlamydomonas were grown in $1.0 \mathrm{~L}$ of their respective media in $1.5 \mathrm{~L}$ Pyrex glass cylindrical bioreactors under fluorescent lighting of $150 \mu \mathrm{E} / \mathrm{m}^{2} / \mathrm{s}$ at $28^{\circ} \mathrm{C}$. Cells were kept suspended by aerating at a $1 \mathrm{~L}$ per min flow rate. Cyanidioschyzon was grown similarly except that the temperature was maintained at $45^{\circ} \mathrm{C}[53]$.

\section{Cell treatments}

The effect of sulfur nutrition on heavy metal resistance and biotransformation was investigated by exposing each species to supplemental sulfur treatments. Supplemental sulfur was provided in the form of sulfate, sulfite or cysteine. Sulfate and sulfite were added as $\mathrm{K}_{2} \mathrm{SO}_{4}$ and $\mathrm{K}_{2} \mathrm{SO}_{3}$, respectively, at ten-fold the amount of sulfur equivalents in the original media and the L-cysteine treatments were supplemented to twice the original amount of sulfur equivalents in the media. Experimental treatments included 1) no additional sulfur containing compounds, 2) additional sulfur containing compound, and 3) additional sulfur containing compound both before (pre-fed) and during the treatment period (plus). All treatments were performed in $100 \mathrm{~mL}$ of medium in $150 \mathrm{~mL}$ glass plant tissue culture vessels with translucent magenta B-caps obtained from Sigma-Aldrich (Oakville, Canada). Continuous fluorescent illumination was at $150 \mu \mathrm{E} / \mathrm{m}^{2} / \mathrm{s}$ with $120 \mathrm{rpm}$ rotary shaking. Culturing temperatures were $27^{\circ} \mathrm{C}$ for Synechococcus and Chlamydomonas, and $45^{\circ} \mathrm{C}$ for Cyanidioschyzon. The initial cell density for all cultures was O.D.665 $=0.1$. These were grown to an O.D. $665=1.0$ and diluted tenfold with fresh media prior to metal treatments. Metal treatments were then performed in one hundred $\mathrm{mL}$ cell cultures in $150 \mathrm{~mL}$ glass cell culture jars, to which $\mathrm{Cd}$ (II) was added from a $25 \mathrm{mM} \mathrm{CdCl}_{2}$ stock solution. A metal ion concentration was selected for each species that slowed but did not stop growth. Cell growth 
was measured at O.D.665 using a Spectra Max Plus Spectrophotometer (Molecular Devices, Sunnyvale, CA).

\section{Sulfide analysis}

Analysis of acid labile sulfide was performed using a modified version of the protocol developed by Siegel [27]. One hundred microliter samples from the cell cultures were transferred into $1.5 \mathrm{~mL}$ microcentrifuge

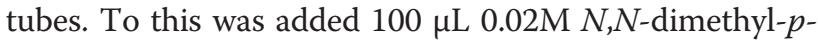
phenylenediamine sulfate in $7.2 \mathrm{~N} \mathrm{HCl}$ and $100 \mu \mathrm{L}$ of $0.3 \mathrm{M} \mathrm{FeCl}_{3}$ in $1.2 \mathrm{~N} \mathrm{HCl}$. Parafilm was used to seal the microcentrifuge caps, followed by incubation in the dark for $20 \mathrm{~min}$. and centrifugation at $10,000 \times \mathrm{g}$ for $10 \mathrm{~min}$. at room temperature. Two hundred microliters of supernatant was then transferred into the wells of a 96 well plate and optical density was measured at $670 \mathrm{~nm}$ using a Spectra Max Plus Spectrophotometer. Concentrations were determined by comparing results to standard curves developed with $\mathrm{Na}_{2} \mathrm{~S}$ standards.

\section{Enzyme assays}

Ten millilitre samples were removed from $100 \mathrm{~mL}$ cultures at intervals of $0,6,12,24$ and $48 \mathrm{~h}$, transferred into $15 \mathrm{~mL}$ screw capped polypropylene centrifuge tubes (VWR 21008-089) and centrifuged at 3,000 $g$ for 10 minutes at $4^{\circ} \mathrm{C}$. The supernatant was removed, and the pellets were gently resuspended in $1 \mathrm{~mL}$ of ice cold 10 $\mathrm{mM}$ potassium phosphate buffer ( $\mathrm{pH}$ 7.5) [69] and transferred to $1.5 \mathrm{~mL}$ microfuge tubes. Then, $0.05 \mathrm{~g}$ of $0.1 \mathrm{~mm}$ glass beads were added to each tube followed by homogenization for 5 minutes at maximum speed using a Bullet Blender (Next Advance, Averill Park, NY) . Homogenized samples were then frozen in liquid nitrogen and stored at $-80^{\circ} \mathrm{C}$ until required.

The serine acetyl-transferase (SAT) and $O$-acetylserine (thiol)lyase (OASTL) combined enzyme assay was modified from Dominguez et al. [5]. One hundred microliters of cellular lysate was added to a $1.5 \mathrm{~mL}$ microcentrifuge tube, along with $20 \mu \mathrm{L}$ of $100 \mathrm{mM}$ potassium phosphate buffer ( $\mathrm{pH}$ 7.3). Then, $9.5 \mu \mathrm{L}$ of $400 \mathrm{mM} \mathrm{L}$-serine was added to the reaction tube followed by $6.75 \mu \mathrm{L}$ of 400 $\mathrm{mM}$ acetyl coenzyme A, $10 \mu \mathrm{L}$ of $100 \mathrm{mM} \mathrm{Na}_{2} \mathrm{~S}$ and 72 $\mu \mathrm{L}$ of double deionized water. The samples were immediately mixed by vortexing and incubated at $30^{\circ} \mathrm{C}$ for 20 min. The reaction was then terminated through the addition of $25 \mu \mathrm{L}$ of $25 \%$ trichloroacetic acid. The Lcysteine produced was measured by transferring $200 \mu \mathrm{L}$ of the sample into $5 \mathrm{~mL}$ test tubes containing $0.2 \mathrm{~mL}$ of 99.5\% acetic acid ninhydrin reagent. The ninhydrin reagent was composed of $250 \mathrm{mg}$ ninhydrin in $6 \mathrm{~mL}$ glacial acetic acid and $4 \mathrm{~mL}$ concentrated $\mathrm{HCl}$ made daily. This was mixed for 30 minutes in the dark at room temperature before use. The test tubes were then placed into a $100^{\circ} \mathrm{C}$ water bath for $10 \mathrm{~min}$ followed by rapid cooling in wet ice. The ninhydrin reaction was terminated by the addition of $1.4 \mathrm{~mL}$ of $99 \%$ ethanol. Two hundred microliter samples were then read on a Spectra Max Plus Spectrophotometer at $560 \mathrm{~nm}$ and concentrations determined by comparison with cysteine standards. Enzymatic activities are presented on a per protein basis.

Cysteine desulfhydrase activity was determined by following a modified protocol from $\mathrm{Chu}$ and colleagues [69]. One hundred microliter samples in $10 \mathrm{mM}$ potassium phosphate buffer were transferred to $1.5 \mathrm{~mL}$ microcentrifuge tubes. The reactions were initiated by the addition of $900 \mu \mathrm{L} 0.11 \mathrm{mM} \mathrm{L}$-cysteine followed by vortexing and incubated at $37^{\circ} \mathrm{C}$ for $1 \mathrm{~h}$. Sulfide production was quantified by following the protocol described above in the sulfide analysis section [27].

\section{Protein assays}

Bradford assays were determined by following the protein microplate bioassay procedure supplied by Bio-Rad (Mississauga, Canada). Protein Assay Dye Reagent concentrate was diluted 5 times in distilled water. Ice-cold samples were homogenized using a Bullet Blender (Next Advance, Averill Park, NY) for 5 minutes on its maximum speed. The homogenized cells were then transferred into fresh $1.5 \mathrm{~mL}$ microcentrifuge tubes and centrifuged at $1000 \mathrm{~g}$ for $5 \mathrm{~min}$ to pellet cellular debris. Then $80 \mu \mathrm{L}$ samples from the supernatant were diluted with $720 \mu \mathrm{L}$ of double deionized water. To this $200 \mu \mathrm{L}$ of dye reagent was added to each tube, vortexed and the samples incubated at room temperature for 5 minutes. Two hundred microliter aliquots were then read at $595 \mathrm{~nm}$ in a Spectra Max Plus Spectrophotometer.

\section{Statistics}

Analysis of variance (ANOVAS) and Tukey-Kramer post hoc tests were performed using JMP 8.0 software (SAS Incorporated.), or where appropriate, T-tests were analyzed using Microsoft Excel 2007. All experiments include representative standard errors (SE). Experiments were performed at least in triplicate and the results are indicative of $n=3$ for enzymatic assays. SE is presented in all figures by the error bars. Where it is not visible, SE is smaller than the character at that point.

\section{Competing interests}

The authors declare that they have no competing interests.

\section{Authors' contributions}

CDE: metal tolerance analysis, sulfide measurements, enzyme activity analysis, interpretation of data, manuscript suggestions. JCB: cell culture of

Chlamydomonas, analysis of cysteine desulfhydrase activity. JBRL: cell culture of Cyanidioschyzon, sulfide and enzyme activity analysis. KAV: cell culture of Synechococcus, sulfide and enzyme activity analysis. DDL: conception and design, supervision of the research group, funding support, drafting and revising the manuscript. All authors approved the final manuscript. 


\section{Acknowledgements}

This research was supported by Natural Sciences and Engineering Council of Canada and the Advisory Research Committee of Queen's University.

Received: 27 February 2013 Accepted: 5 July 2013

Published: 15 July 2013

\section{References}

1. Elinder CG, Kjellström T, Hogstedt C, Andersson K, Spång G: Cancer mortality of cadmium workers. Br J Ind Med 1985, 42:651-656.

2. Garcia-Morales P, Saceda M, Kenney N, Kim N, Salomon D, Gottardis M, Solomon $\mathrm{H}$, Sholler $\mathrm{P}$, Jordan V, Martin M: Effect of cadmium on estrogen receptor levels and estrogen-induced responses in human breast cancer cells. J Biol Chem 1994, 269:16896-16901.

3. Sataruga S, Haswell-Elkinsa MR, Moorea MR: Safe levels of cadmium intake to prevent renal toxicity in human subjects. Br J Nutr 2000, 84:791-802.

4. Heng L, Jusoh K, Ling C, Idris M: Toxicity of single and combinations of lead and cadmium to the cyanobacteria Anabaena flos-aquae. Bull Environ Contam Toxicol 2004, 72:373-379.

5. Dominguez M, Gutierrez F, Leon R, Vilchez C, Vega J, Vigara J: Cadmium increases the activity levels of glutamate dehydrogenase and cysteine synthase in Chlamydomonas reinhardtii. Plant Physiol Biochem 2003, 41:828-832

6. Gouia H, Ghorbal M, Meyer C: Effects of cadmium on activity of nitrate reductase and on other enzymes of the nitrate assimilation pathway in bean. Plant Physiol Biochem 2000, 38:629-638.

7. Mosulen S, Dominguez M, Vigara J, Vilchez C, Guiraum A, Vega J: Metal toxicity in Chlamydomonas reinhardtii. Effect on sulfate and nitrate assimilation. Biomol Eng 2003, 20:199-203.

8. Rai LC, Tyagi B, Rai PK, Mallick N: Interactive effects of UV-B and heavy metals ( $\mathrm{Cu}$ and $\mathrm{Pb}$ ) on nitrogen and phosphorus metabolism of a N2-fixing cyanobacterium Anabaena doliolum. Environ Exp Bot 1998, 39:221-231.

9. Voigt J, Nagel K: The donor side of photosystem II is impaired in a $\mathrm{Cd} 2+-$ tolerant mutant strain of the unicellular green alga Chlamydomonas reinhardtii. J Plant Physiol 2002, 159:941-950.

10. Permina EA, Kazakov AE, Kalinina OV, Gelfand MS: Comparative genomics of regulation of heavy metal resistance in Eubacteria. BMC Microbiology 2006, 6:49-49.

11. Dominguez-Solis J, Lopez-Martin M, Ager F, Ynsa M, Romero L, Gotor C: Increased cysteine availability is essential for cadmium tolerance and accumulation in Arabidopsis thaliana. Plant Biotechnol J 2004, 2:469-476.

12. Houot L, Floutier M, Marteyn B, Michaut M, Picciocchi A, Legrain P, Aude J, Cassier-Chauvat C, Chauvat F: Cadmium triggers an integrated reprogramming of the metabolism of Synechocystis PCC6803, under the control of the SIr1738 regulator. BMC Genomics 2007, 8:350.

13. Kelly D, Budd K, Lefebvre DD: Mercury analysis of acid- and alkalinereduced biological samples: identification of meta-cinnabar as the major biotransformed compound in algae. Appl Environ Microbiol 2006, 72:361-367.

14. Kelly DJA, Budd K, Lefebvre DD: Biotransformation of mercury in $\mathrm{pH}$-stat cultures of eukaryotic freshwater algae. Arch Microbiol 2007, 187:45-53.

15. Lefebvre DD, Kelly D, Budd K: Biotransformation of $\mathrm{Hg}$ (II) by cyanobacteria. Appl Environ Microbiol 2007, 73:243-249.

16. Kelly DJA, Budd K, Lefebvre DD: The biotransformation of mercury in $\mathrm{pH}$ stat cultures of microfungi. Can J Bot 2006, 84:254-260.

17. Mendoza-Cozatl D, Loza-Tavera H, Hernandez-Navarro A, Moreno-Sanchez R: Sulfur assimilation and glutathione metabolism under cadmium stress in yeast, protists and plants. FEMS Microbio/ Rev 2004, 29:653-671.

18. Payne CD, Price NM: Effects of cadmium toxicity on growth and elemental composition of marine phytoplankton. J Phycol 1999, 35:293-302.

19. Perales-Vela HV, Peña-Castro JM, Cañizares-Villanueva RO: Heavy metal detoxification in eukaryotic microalgae. Chemosphere 2006, 64:1-10.

20. Thorsen M, Perrone GG, Kristiansson E, Traini M, Ye T, Dawes IW, Nerman O, Tamás MJ: Genetic basis of arsenite and cadmium tolerance in Saccharomyces cerevisiae. BMC Genomics 2009, 10:105-119.

21. Gill SS, Tuteja N: Cadmium stress tolerance in crop plants. Probing the role of sulfur. Plant Signal Behav 2011, 6:215-222.

22. Peraza MA, Ayala-Fierro F, Barber DS, Casarez E, Rael LT: Effects of micronutrients on metal toxicity. Environ Health Perspect 1998, 106 Supplement 1:203-216.
23. Rabinowitch H, Fridovich I: Growth of Chlorella sorokiniana in the presence of sulfite elevates cell content of superoxide dismutase and imparts resistance towards paraquat. Planta 1985, 164:524-528.

24. Niknahad $\mathrm{H}, \mathrm{O}^{\prime}$ Brien PJ: Mechanism of sulfite cytotoxicity in isolated rat hepatocytes. Chem Biol Interact 2008, 174:147-154

25. Bakels RHA, Vanwalraven HS, Vanwielink JE, Vanderzwetdegraaff I, Krenn BE, Krab K, Berden JA, Kraayenhof R: The effect of sulfite on the ATP hydrolysis and synthesis activity of membrane-bound $\mathrm{H}^{+}$-ATP synthase from various species. Biochem Biophys Res Commun 1994, 201:487-492.

26. Moriarty-Craige S, Jones D: Extracellular thiols and thiol/disulfide redox in metabolism. Annu Rev Nutr 2004, 24:481-509.

27. Siegel LM: A direct microdetermination for sulfide. Anal Biochem 1965 11:126-132.

28. Gueldry O, Lazard M, Delort F, Dauplais M, Grigoras I, Blanquet S, Plateau P. Ycf1p-dependent $\mathrm{Hg}$ (II) detoxification in Saccharomyces cerevisiae. Eur JBiochem 2003, 270:2486-2496.

29. Li Z, Lu Y, Zhen R, Szczypka M, Thiele D, Rea P: A new pathway for vacuolar cadmium sequestration in Saccharomyces cerevisiae: YCF1-catalyzed transport of bis(glutathionato)cadmium. Proc Natl Acad Sci USA 1997 94:42-47.

30. Bierkens J, Maes J, Plaetse FV: Dose-dependent induction of heat shock protein 70 synthesis in Raphidocelis subcapitata following exposure to different classes of environmental pollutants. Environ Pollu 1998, 101:91-97.

31. El-Enany $A E$, Issa $A A$ : Cyanobacteria as a biosorbent of heavy metals in sewage water. Environ Toxicol Pharmacol 2000, 8:95-101.

32. Torres E, Cid A, Fidalgo P, Herrero C, Abalde J: Long-chain class III metallothioneins as a mechanism of cadmium tolerance in the marine diatom Phaeodactylum tricornutum Bohlin. Aquat Toxicol 1997, 39:231-246.

33. Scarano G, Morelli E: Properties of phytochelatin-coated CdS nanocrystallites formed in a marine phytoplanktonic alga (Phaeodactylum tricornutum, Bohlin) in response to Cd. Plant Sci 2003, 165:803-810.

34. Aranda A, JimÃ@nez-MartÃ E, Orozco H, Matallana E, del Olmo M: Sulfur and adenine metabolisms are linked, and both modulate sulfite resistance in wine yeast. J Agric Food Chem 2006, 54:5839-5846.

35. Nardi T, Corich V, Giacomini A, Blondin B: A sulphite-inducible form of the sulphite efflux gene SSU1 in a Saccharomyces cerevisiae wine yeast. Microbiology 2010, 156:1686-1696.

36. Pinto G, Albertano P, Ciniglia C, Cozzolino S, Pollio A, Yoon H, Bhattacharya D: Comparative approaches to the taxonomy of the genus Galdieria merola (Cyanidiales, Rhodophyta). Cryptogam Algol 2003, 24:13-32.

37. Allen MB: Studies with Cyanidium caldarium, an anomalously pigmented chlorophyte. Arch Mikrobiol 1959, 32:270-277.

38. Murasugi A, Wada C, Hayashi Y: Occurrence of acid-labile sulfide in cadmium-binding peptide 1 from fission yeast. J Biochem 1983, 93:661-664

39. Gupta A, Whitton BA, Morby AP, Huckle JW, Robinson NJ: Amplification and rearrangement of a prokaryotic metallothionein locus smt in Synechococcus PCC 6301 selected for tolerance to cadmium. P Roy Soc B-Biol Sci 1992, 248:273-281

40. Scarano G, Morelli E: Characterization of cadmium- and leadphytochelatin complexes formed in a marine microalga in response to metal exposure. Biometals 2002, 15:145-151.

41. Holmes JD, Smith PR, Evans-Gowing R, Richardson DJ, Russell DA, Sodeau JR: Energy-dispersive X-ray analysis of the extracellular cadmium sulfide crystallites of Klebsiella aerogenes. Arch Microbiol 1995, 163:143-147.

42. Reese RN, White CA, Winge DR: Cadmium-sulfide crystallites in Cd-( $(\mathrm{EC})$ nG peptide complexes from tomato. Plant Physiol 1992, 98:225-229.

43. Speiser DM, Abrahamson SL, Banuelos G, Ow DW: Brassica juncea produces a phytochelatin-cadmium-sulfide complex. Plant Physiol 1992, 99:817-821

44. Melis $\mathrm{A}$, Chen $\mathrm{H}$ : Chloroplast sulfate transport in green algae - genes, proteins and effects. Photosynth Res 2005, 86:299-307.

45. Merchant SS, Prochnik SE, Vallon O, Harris EH, Karpowicz SJ, Witman GB, Terry A, Salamov A, Fritz-Laylin LK, Marechal-Drouard L, Marshall WF, Qu L, Nelson DR, Sanderfoot AA, Spalding MH, Kapitonov W, Ren Q, Ferris P, Lindquist E, Shapiro H, Lucas SM, Grimwood J, Schmutz J, Cardol P, Cerutti H, Chanfreau G, Chen C, Cognat V, Croft MT, Dent R, et al: The Chlamydomonas genome reveals the evolution of key animal and plant functions RID A-3530-2008 RID A-1214-2009 RID A-1755-2010 RID C-1537-2010. Science 2007, 318:245-251. 
46. Pollock SV, Pootakham W, Shibagaki N, Moseley JL, Grossman AR: Insights into the acclimation of Chlamydomonas reinhardtii to sulfur deprivation. Photosynth Res 2005, 86:475-489.

47. Kertesz MA: Bacterial transporters for sulfate and organosulfur compounds. Res Microbiol 2001, 152:279-290.

48. Smith FW, Hawkesford MJ, Prosser IM, Clarkson DT: Isolation of a CDNA from Saccharomyces cerevisiae that encodes a high affinity sulphate transporter at the plasma membrane. Mol Gen Genet 1995, 247:709-715.

49. Hawkesford MJ, De Kok L: Managing sulphur metabolism in plants. Plant Cell Environ 2006, 29:382-395

50. Takahashi H, Yamazaki M, Sasakura N, Watanabe A, Leustek T, Engler JA, Engler G, Van Montagu M, Saito K: Regulation of sulfur assimilation in higher plants: a sulfate transporter induced in sulfate-starved roots plays a central role in Arabidopsis thaliana. Proc Natl Acad Sci USA 1997, 94:11102-11107.

51. Giordano M, Norici A, Hell R: Sulfur and phytoplankton: acquisition, metabolism and impact on the environment. New Phytol 2005, 166:371-382.

52. Ravina CG, Barroso C, Vega JM, Gotor C: Cysteine biosynthesis in Chlamydomonas reinhardtii. Molecular cloning and regulation of O-acetylserine(thiol)lyase. Eur J Biochem 1999, 264:848-853.

53. Gross W, Kuver J, Tischendorf G, Bouchaala N, Busch W: Cryptoendolithic growth of the red alga Galdieria sulphuraria in volcanic areas. Eur J Phycol 1998, 33:25-31.

54. Gross W, Oesterhelt C: Ecophysiological studies on red alga Galdieria sulphuraria isolated from southwest iceland. Plant Biol 1999, 1:694-700.

55. Nozaki H, Toda K, Takano H, Kuroiwa T: The second serine acetyltransferase, bacterial-type O-acetylserine (thiol) lyase and eukaryotic-type O-acetylserine (thiol) lyase from the primitive red alga Cyanidioschyzon merolae. J Plant Res 2001, 114:291-300.

56. Ning $H$, Zhang $C$, Yao $Y, Y u$ D: Overexpression of a soybean $O$ acetylserine (thiol) lyase-encoding gene GMOASTL4 in tobacco increases cysteine levels and enhances tolerance to cadmium stress. Biotech Lett 2010, 32:557-564.

57. Kawashima CG, Noji M, Nakamura M, Ogra Y, Suzuki KT, Saito K: Heavy metal tolerance of transgenic tobacco plants over-expressing cysteine synthase. Biotech Lett 2004, 26:153-157.

58. Chen J, Wu F, Wang W, Zheng C, Lin G, Dong X, He J, Pei Z, Zheng H: Hydrogen sulphide enhances photosynthesis through promoting chloroplast biogenesis, photosynthetic enzyme expression, and thiol redox modification in Spinacia oleracea seedlings. J Exp Bot 2011, 62:4481-4493

59. Hancock JT, Lisjak M, Teklic T, Wilson ID, Whiteman M: Hydrogen sulphide and signalling in plants. $C A B$ Reviews: Perspectives in Agriculture, Veterinary Science, Nutr Nat Res 2011, 6:1-7.

60. Papenbrock J, Riemenschneider A, Kamp A, Schulz-Vogt H, Schmidt A: Characterization of cysteine-degrading and $\mathrm{H}_{2} \mathrm{~S}$-releasing enzymes of higher plants - from the field to the test tube and back. Plant Biol 2007, 9:582-588.

61. Sekiya J, Schmidt A, Wilson LG, Filner P: Emission of hydrogen sulfide by leaf tissue in response to L-cysteine. Plant Physiol 1982, 70:430-436.

62. Wilson LG, Bressan RA, Filner P: Light-dependent emission of hydrogen sulfide from plants. Plant Physiol 1978, 61:184-189.

63. Rennenberg $\mathrm{H}$ : Role of $\mathrm{O}$-acetylserine in hydrogen sulfide emission from pumpkin leaves in response to sulfate. Plant Physiol 1983, 73:560-565.

64. Wang C, Maratukulam P, Lum A, Clark D, Keasling J: Metabolic engineering of an aerobic sulfate reduction pathway and its application to precipitation of cadmium on the cell surface. Appl Environ Microbiol 2000, 66:4497-4502

65. Wang CL, Lum AM, Ozuna SC, Clark DS, Keasling JD: Aerobic sulfide production and cadmium precipitation by Escherichia coli expressing the Treponema denticola cysteine desulfhydrase gene. Appl Microbiol Biotechnol 2001, 56:425-430.

66. Bai HJ, Zhang ZM, Guo Y, Yang GE: Biosynthesis of cadmium sulfide nanoparticles by photosynthetic bacteria Rhodopseudomonas palustris. Coll Surf B: Biointerfaces 2009, 70:142-146.
67. Sueoka N, Chiang KS, Kates JR: Deoxyribonucleic acid replication in meiosis of Chlamydomonas reinhardi I. Isotopic transfer experiments with a strain producing eight zoospores. J Mol Biol 1967, 25:47-66.

68. Rippka R, Waterbury J, Cohen-Bazire G: A cyanobacterium which lacks thylakoids. Arch Microbiol 1974, 100:419-436.

69. Chu L, Ebersole J, Kurzban G, Holt S: Cystalysin, a 46-kilodalton cysteine desulfhydrase from Treponema denticola, with hemolytic and hemoxidative activities. Infect Immun 1997, 65:3231-3238.

doi:10.1186/1471-2180-13-161

Cite this article as: Edwards et al:: Aerobic transformation of cadmium through metal sulfide biosynthesis in photosynthetic microorganisms. BMC Microbiology 2013 13:161.

\section{Submit your next manuscript to BioMed Central and take full advantage of:}

- Convenient online submission

- Thorough peer review

- No space constraints or color figure charges

- Immediate publication on acceptance

- Inclusion in PubMed, CAS, Scopus and Google Scholar

- Research which is freely available for redistribution

Submit your manuscript at www.biomedcentral.com/submit
C) BioMed Central 